\title{
The Reform of Social Security System and the Internal and External Rebalance of China's Economy
}

\author{
QIAN Yuzhuo \\ College of Economics and Management, Baicheng Normal University, Baicheng, 137000, China \\ email: 8438136@qq.com
}

\begin{abstract}
Keywords: Social Security System, Reform, China's Economy, the Internal and External Rebalance
\end{abstract}

\begin{abstract}
In recent years, the country has paid more and more attention to the social security work, increased the investment in the social security industry, promoted the development of social security, improved the quality of life of the residents, and promoted the overall consumption level of our country. The reform and innovation of the social security system has promoted the internal and external rebalancing of our economy. Therefore, it is necessary to discuss the reform of the social security system and the internal and external rebalancing of the Chinese economy.
\end{abstract}

\section{Introduction}

With the deepening of economic reform, people's life has improved significantly. At the same time, some old, weak, sick and disabled people need to pay more attention to the whole society. The importance of social security is more prominent. Whether the social security system is perfect or not is directly related to the development of the social economy and the internal and external economic equilibrium. Therefore, according to our country's national conditions, the old social security system is supplemented and perfected, so as to improve people's consumption level, to form a scientific and reasonable economic structure and economic system, to effectively solve the imbalance of investment shortage and resource waste.

\section{Social Security System}

The social security is in the country as the main body. In the government management, with certain laws and regulations as the basis, through the redistribution of the national income by the social security fund as the basis for some temporary or permanent incapacity of citizens, or because of various reasons some citizens life difficult, given the corresponding material help, in order to protect the basic living needs of the residents. The funds of the social security system mainly comes from the collective insurance, personal insurance, government funding, compulsory savings measures to raise the standard of living, the state is not up to the minimum standards of civil implementation assistance, to provide basic living guarantee for temporary or permanent incapacity the people, all members of society to gradually improve the material and cultural well-being, the nature of social security is to maintain social fairness and promote social stability and development of social security. The improvement of the Department has become one of the important symbols of the progress of social civilization[1].

\section{The Influence of Social Security System on China's Economy}

Social Security and high Savings Rate. The social security system is perfect or not is directly related to residents' income, risk prevention ability and consumption rate. Usually, the lower the household income, the higher the risk of illness and accidents[2]. On the contrary, the higher the income level, the stronger the ability to deal with and bear all kinds of risks, that is to say. The improvement of the level of social security plays a greater role in the low and middle income groups, but the overall level of our social security system is low, the structure is not balanced, the organs and enterprises. Institutions relatively high income groups social security system is relatively 
perfect, enjoy five risks and one gold treatment, while migrant workers, private enterprises, individual workers and other low-income groups of social security is inadequate. Even many do not have the treatment of "five risks and one gold" at all. The social security is insufficient, the residents have to make the safeguard for their own future risk prevention, save the funds ahead of time, the resident consumption level reduces, the consumption rate drops. The proportion of consumer expenditure in the economy continues to decline, according to statistics, the proportion of consumer expenditure in previous years has dropped by nearly $1 / 4$, household consumption expenditure growth rate is slow. In the rapid economic development of the general environment, domestic demand shrank[3].

The Influence of Social Security Income Level on Household Consumption in Urban and Rural Areas. The level of social security income is directly related to the consumption expenditure of urban and rural households. The increase of social security income of urban and rural households can promote the consumption expenditure of urban and rural families, compared with the increase of social security income. Urban household consumption expenditure is more than the increase rate of rural household consumption expenditure, due to the low level of social security in China, the system is not perfect. The effect of the increase of social security income on the increase of household consumption expenditure is not significant, because the social security system of our country is not perfect enough. So that urban and rural residents only rely on old-age insurance and medical insurance and other social security can not completely relieve the worries, most urban and rural families will increase the income through the way of savings, used for risk prevention. In order to ensure the future of security and stability of life.

Insufficient Social Security and Unbalanced Industrial Structure. Due to insufficient social security and insufficient financial investment, some SMEs have difficulty in financing the stock market, while bank loans are inclined to large and medium-sized enterprises, with guarantee or policy support, loans are easier and SMEs have difficulty in financing. In order to promote the rapid development of the economy, the government can only lead passively, but because of the lack of social security, the consumption level of residents is low. Consumption industry and service industry demand decreased, the government's leading investment can only passively tend to infrastructure, high-consumption industries or export-oriented industries to supplement the lack of domestic demand. Lead to the imbalance of industrial structure and internal and external economic imbalance[4].

The Influence of Different Types of Social Security System on the Household Consumption of Urban and Rural Residents. Different types of social security systems also have different effects on the consumption of urban and rural residents. For example, for the old-age insurance, with the aging of the population in China, the proportion of the elderly population increases. In order to increase the social security for the elderly and increase the expenditure of the old-age insurance, the old-age insurance can make the urban and rural residents to have the protection, the old has the basis, has increased the sense of security to the elderly life[5]. It enhances the safety and stability of the family life of the urban and rural residents, can safely consume, and to a certain extent promotes the consumption of the urban and rural families, while the medical insurance system provides protection for the residents' health and medical treatment. Reduce and avoid the risk that urban and rural residents have to bear because of medical problems, and promote the safety and stability of urban and rural residents' life. Medical insurance provides more protection for urban and rural residents, reduces the medical investment of urban and rural residents, can be more comfortable to consume, so medical insurance can help to improve the level of consumption of urban and rural residents.

The Price of the Basic Resource Factors Caused by Social Security is Reduced, Resulting in Waste of Resources. In economic development, labor force, savings capital and natural resources are the essential basic elements. The price of labor force and savings capital is determined by the relationship between supply and demand. When the social security is insufficient, residents are better to guard against risks. In order to obtain more income as consumer funds, the willingness of voluntary savings is strong, willing to reduce the remuneration of labor to pay for labor, so that the 
price of labor and savings capital is suppressed. The price of natural resources is basically determined by the government, and the government should lead the investment in the underinvested sector, so the government can only reduce the price of natural resources and reduce the investment costs. In this way, the resource consumption rate of our country in economic development is high, even the phenomenon of resource waste, which makes the social and economic development out of balance[6].

\section{Reform Measures of Social Security System}

To Improve the Fairness of the Social Security System. Because of the difference between urban and rural areas and the imbalance of economic development between regions, there is an unfair phenomenon in the social security system, and there is a lack of overall concept in the design of the system and a weak sense of fairness. Therefore, to improve the fairness of the social security system, better meet the needs of the masses, strengthen the top design of the social security system, the system should be oriented to the whole country. Meet the needs of the majority of residents, ensure that everyone has the same rights to be protected, fair and just, integrate the original fragmented social security system, and carry out reform and innovation. Gradually form a unified urban-rural social security system consisting of old-age insurance, medical security insurance and minimum living security system, to reflect the fairness of civil rights, and establish a unified urban and rural social security management institutions. To implement a unified management model and ensure the fair operation of the system. Gradually realize the universal participation insurance, unemployment, childbirth, industrial injury and other insurance "should be fully insured". To ensure the fairness and coverage of the system. Further promote the social security system other than the basic social security system of all kinds of social security work equity development, through the work to enhance citizens' sense of access to security and sense of equality. Strengthen social cohesion, gradually narrow the gap between urban and rural economic development, and promote the balance of urban and rural economic development.

We should Improve the System of Social Security System so as to Improve the Capacity of the Residents to Pay. To establish and improve the scientific and long-term social security system, to solve the problems of repeated insurance coverage, leakage of insurance, removal of insurance, and so on, to step up publicity, enhance the awareness of urban and rural residents to participate in the insurance, and improve the possibility of the whole people participating in the insurance. In order to improve the whole society's ability and level of social security payment. In view of the problem that some small and medium enterprises' social security payment ability is insufficient, some employees will interrupt the social security payment due to unemployment or other reasons, and even get rid of the insurance finally. We will establish and improve the mobilization and incentive system for participating in insurance, give appropriate incentives and encouragement to residents who are insured on time and pay in time, and mobilize the enthusiasm and initiative of the broad masses of residents to participate in the payment of insurance fees, according to statistics. The number of the old-age insurance and medical insurance in our country is less than the number of employed people every year, so we should expand the coverage of social security for employed persons. To promote the participation of the whole people. Establish a scientific and reasonable pension insurance transfer succession system to reduce and avoid the possibility of breaking the insurance and taking off the insurance. For some temporary workers, the mobility is greater, there are some people because of their ability. Education, quality and other reasons of unemployment is inevitable, coupled with some young people like to switch jobs, especially some fresh graduates of college students, frequent changes of posts, these lead to the end of the insurance, the phenomenon of insurance increased. It is more important to establish a scientific and reasonable system of social security relationship transfer, and then to make the missing insurance, the withdrawal of insurance personnel can normally pay, improve the effect of social security, and improve the supervision mechanism of social security system. Repeated participation in insurance and the use of duties in order to obtain personal benefits, strict punishment, ensure the quality of social security contributions[7]. 
We will Narrow the Gap between Urban and Rural Residents' Consumption. The establishment and perfection of the social security system is a difficult and complex work, which has a long way to go. According to the specific situation of our country, it is not only necessary to make appropriate adjustments to the original social security expenditure system. We should shift the focus of social security from urban to rural, increase the investment of social security funds in rural areas, and improve the serious lack of social security funds in rural households. Economic structure and other reasons, such as family income is much lower than urban residents, the local social security system is not perfect, enjoy low social security treatment and even some rural residents in remote areas did not enjoy social security treatment at all. Therefore, governments at all levels should, according to the actual local conditions, start from each family and strengthen social security work, especially to further improve the medical security system in rural areas. To reduce and avoid the phenomenon of rural residents being poor and destitute because they can not afford expensive medical treatment. Through the perfection of social security system, the gap between urban and rural areas can be narrowed and the balance of economic development will be promoted.

We will Strengthen the Consumer Confidence of Urban and Rural Households. Through the continuous improvement of the social security system, analysis of the existing problems, make up for and amend the weak links in the original system, so that the social security system covers a wider range of people involved more diverse. Constantly expand the scope of social security work, so that different regions, different levels, different income levels of all kinds of families can enjoy social security. To make the residents feel the superiority of the social master system and the warmth of the big family of the motherland, so as to ensure the fair and just process of the implementation of the social security system. Starting from the reality, we should comprehensively investigate the level of per capita income and consumption in different regions, pay attention to regional differences, and formulate social security standards that accord with the characteristics of different regions. So that families at different levels can realize the sense of security brought by the social security system, so that the social security system more targeted and effective, to relieve the worries of urban and rural residents consumption, enhance consumer confidence. Improve the consumption level of urban and rural families, promote the benign cycle of our economy and the balance of economic development inside and outside, and promote the vigorous development of our economy[8].

Improve the Structure of Social Security Income. In the process of continuous improvement and development of social security system, although the rural residents' social security income and consumption level are still far lower than urban families, only to narrow the income gap between urban and rural households. Therefore, we should improve the expenditure structure of social security, increase the public finance in the field of social security investment, especially to rural social security investment. Reduce rural residents' consumption worries, make them more practical, more secure. At the same time, strict use of rural social security funds, for unauthorized use of social security funds, interception. In order to make the social security fund play a greater role in urban and rural families, we should seize the bad behavior of social security income that should be issued to the residents, strictly punish and punish it according to the seriousness of the circumstances, optimize the social security expenditure and make the social security funds play a greater role in the urban and rural families.

Improve the Social Assistance System and Pay Attention to the Vulnerable Groups. Establish and perfect the social assistance system, improve the economic situation of the vulnerable groups, reduce the gap between the rich and the poor. First, we must make clear the mechanism of the object of assistance, according to the characteristics and specific conditions of the poor. Establish an active social assistance system, strictly stipulate the criteria for social assistance, such as family per capita income, the degree of loss suffered by unexpected events, disability levels, and so on, according to different circumstances to give different social assistance. We should not only play an important role in social assistance, but also reflect fairness and justice. Establish a tracking mechanism of social assistance, for those who enjoy social assistance, pay attention to their subsequent living conditions. If you have exceeded the criteria for help, immediately stop the rescue, 
leaving opportunities to those more in need. Severe penalties should be imposed for violations such as relationship insurance, human protection, and so on, and financial investment should be increased. To improve the level and coverage of social assistance, to solve the actual basic life problems for more vulnerable groups, to give full play to the role of social assistance, to improve the social security system, and to promote the internal and external balance of China's economy.

\section{Conclusion}

Social security is the product of the economic development of our country in a certain period, which improves the consumption level of the residents. It is of great significance to promote the economic development of our country. Whether the social security system is perfect or not has a direct impact on the internal and external balance of our economy. Through the elaboration of the social security system, this paper discusses the social security system and the high savings rate. The impact of social security income level on household consumption in urban and rural areas, inadequate social security, unbalanced industrial structure, and the impact of different types of social security systems on household consumption in urban and rural areas. This paper analyzes the impact of social security system on economic development in terms of the reduction of the price of basic resource elements caused by social security and the waste of resources, and improves the fairness of social security system and the improvement of social security system. We should improve residents' ability to pay fees, narrow the consumption gap between urban and rural residents, enhance the consumer confidence of urban and rural families, improve the structure of social security income, improve the social assistance system, and pay attention to the weak groups. Improve the consumption level of residents and promote the balance of domestic and foreign economy. Let us work together to contribute to the rapid development of our economy.

\section{References}

[1] LI Min. The Influence of Supply-side Reform on Social Security System[J].People's Tribune, 2017(29):64-65.

[2] MU Haixia, ZHAO Yunying. Justice: the Value Orientation of Social Security System Reform [J]. Journal of Jinling Institute of Technology(Social Science),2017,31(01):45-48.

[3] WEI Haiyan. New Thinking on the Reform of China's Social Security System[J].Labor Security World, 2015(S1):111-112.

[4] LIU Wenjie. Exploration on the Reform of Rural Social Security System Abroad in Recent Years and Its Enlightenment to China[J].FuJian Agriculture,2015(05):6-7.

[5] MENG Yingying. Reform and Leap Change: China's Practice of Fair and Sustainable Development of Social Security system[J]. Social Security Studies,2014(06):62-68.

[6] SUN Qixiang, XIAO Zhiguang. The Reform of Social Security System and the Rebalance between China's Economic and Outside China[J].Journal of Financial Research,2013(06):74-88.

[7] WANG Yingnan, ZHAO Chenguang. On the Main Influence of Social Security on the Consumption of Urban and Rural Families[J].Money China,2015(02):286.

[8] GUAN Hao. The Influence of Social Security on the Consumption of Urban and Rural Residents[J]. Economic Forum,2013(06):149-151. 